\title{
REMOVAL OF TETRACYCLINE FROM AQUEOUS SOLUTIONS USING NANOSCALE ZERO VALENT IRON AND FUNCTIONAL PUMICE MODIFIED NANOSCALE ZERO VALENT IRON
}

\author{
Ulker Asli GULER \\ Department of Environmental Engineering, Engineering Faculty, Cumhuriyet University, Sivas, Turkey
}

Submitted 16 Feb. 2016; accepted 04 Jul. 2016

\begin{abstract}
Nanoscale zero valent iron (nZVI) and functional pumice modified nanoscale zero valent iron (P-nZVI) were successfully synthesized and used for the removal of tetracycline (TC). These materials were characterized by SEM, TEM, XRD, FTIR, BET. Different factors such as the mass ratio, dosage of adsorbent, $\mathrm{pH}$, initial TC concentration and temperature were investigated. Based on these results; a possible removal mechanism was proposed including $T C$ adsorption and $T C$ reduction via oxidation of $\mathrm{Fe}^{0}$ to $\mathrm{Fe}^{3+}$. In addition, isotherm and thermodynamic parameters were applied to the equilibrium data. The maximum adsorption capacity of TC by nZVI and P-nZVI was $105.46 \mathrm{mg} / \mathrm{g}$ and $115.13 \mathrm{mg} / \mathrm{g}$, respectively. Adsorption and reduction kinetics were examined for the TC removal process. The pseudo-second-order model and pseudo-first-order model was observed for adsorption and reduction process, respectively. Finally, more than $90 \%$ of TC from aqueous solutions was removed by nZVI and P-nZVI.
\end{abstract}

Keywords: tetracyline, antibiotic, characterization, pumice, nanoscale zero valent iron, removal, batch.

\section{Introduction}

Tetracylines (TCs) have been widely used in human therapy and the livestock industry (Zhao et al. 2011). TCs are poorly adsorbed in metabolizm. $30-50 \%$ of the initial TCs amount could be absorbed by digestive tract of humans and animals (Song et al. 2014). Residues of TCs were excreted to the environment via different pathways such as direct discharge of agriculture products and the excretion of substances in livestock urine and feces (Zhao et al. 2011; Boxall 2003). Although TC concentrations and their byproducts were low in the environment, they may lead to development of antibiotic resistant microbial populations as well as environmental and human health problems (Zhao et al. 2011; Daughton, Ternes 1999).

The TC molecule has three multiple ionisable functional groups: a tricarbonylamide group (C-1-C-3), a dimethylammonium group (C-4) and a phenolic diketone group (C-10-C-12) and is amphoteric (Fig. 1) (Zhao et al. 2012; Li et al. 2010; Chen et al. 2011). They can undergo protonation-deprotonation reactions and present different ionic species depending on the solution $\mathrm{pH}$ (Zhao et al. 2011). TC species are a cation $\left(\mathrm{H}_{3} \mathrm{TC}^{+}, \mathrm{pH}<3.3\right)$, neutral $\left(\mathrm{H}_{2} \mathrm{TC}^{0}, 3.3<\mathrm{pH}<7.70\right.$ ), an anion ( $\mathrm{HTC}^{-}, 7.70<\mathrm{pH}<$ 9.70) or two anion ( $\mathrm{TC}^{2-}, \mathrm{pH}>9.70$ ) (Zhao et al. 2012).
Previous studies show that the principal removal mechanism of TC was adsorption process. Natural and nano materials such as goethite (Zhao et al. 2012), activated sludge (Song et al. 2014), kaolinite (Li et al. 2010), clay minerals (Chang et al. 2009a), illite (Chang et al. 2012), and magnetite nanoparticles (Zhang et al. 2011a) have

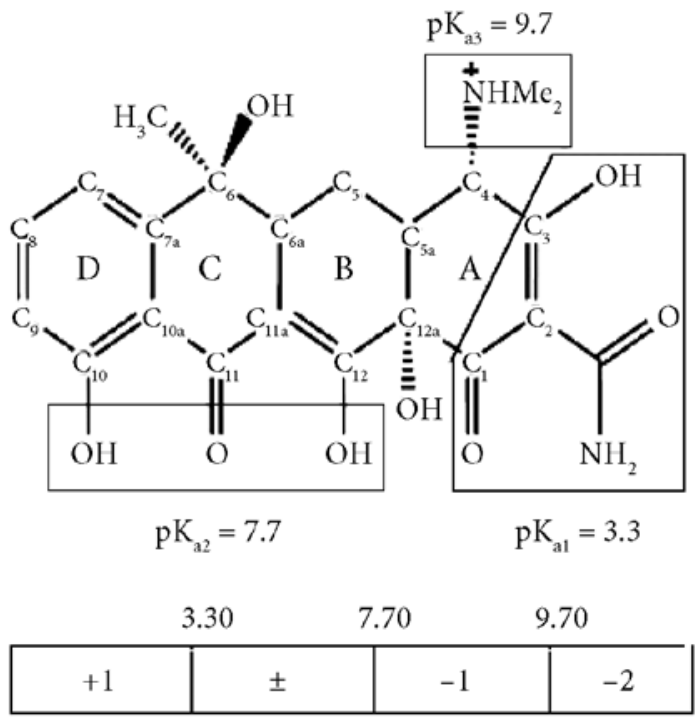

Fig. 1. Structure of TC

Corresponding author: Ulker Asli Guler

E-mail: ulkerasli@gmail.com 
been used in previous studies. Recently, nZVI in powder or granular form has been used to remove pollutants such as heavy metals, chlorinated organic, dyes, pharmaceutical compounds (Fang et al. 2011; Dickinson, Scott 2010; Kim et al. 2013; Li et al. 2012; Chen et al. 2013). This is because of its extremely small particle size, large specific surface area, high density, effective and high reactivity (Üzüm et al. 2009; Cao, Zhang 2006; Kanel et al. 2006). Based on these characteristics, nZVI technology could become a promising approach for treating antibiotic wastewater. However, nZVI has usually been agglomerated in conventional systems along with a decrease in its reactivity and mechanical strength, which have limited its practical applications (Liu et al. 2014; Cumbal et al. 2003). Recently, porous materials such as zeolite (Kim et al. 2013), kaolinite (Üzüm et al. 2009), pillared bentonite (Li et al. 2012) and pillared clay (Zhang et al. 2011b) have been widely used as mechanical supports to enhance the dispersibility of nZVI particles. All of these studies suggest that the use of supported $\mathrm{nZVI}$ is promising for the remediation of contaminated sites (Li et al. 2012). However, some immobilization methods are quite complex, so the development of more efficient immobilization systems is required for practical applications (Li et al. 2012).

Pumice is a light, porous volcanic rock and has a large surface area and skeleton structure (Asgari et al. 2012). Pumice is generally pale in color, ranging from white, cream, blue or grey to greenish-brown or black (Guler, Sarioglu 2014). Pumice has been used in water treatment as a low-cost adsorbent, filter and support media (Fang et al. 2011; Liu et al. 2014; Kitis et al. 2007). Only a few heavy metal removal studies have used pumice with nZVI (Liu et al. 2014; Moraci, Calabro 2010). For these reasons, this study focused on removal of TC onto functional pumice modified nanoscale zero valent iron (P-nZVI). The aim of this study was to understand the removal of TC antibiotic compounds from wastewaters using nZVI and PnZVI. The synthesis of the stable nZVI and P-nZVI composites, characterization, effect of various parameters on the removal process, kinetic studies of the adsorption and reduction process; adsorption isotherms and thermodynamic parameters, and possible removal mechanisms are reported in this study.

\section{Materials and methods}

\subsection{Materials and chemicals}

Pumice was provided by Kayseri-Basakpınar in Turkey and the chemical composition was $69.27 \% \mathrm{SiO}_{2}, 22.1 \%$ $\mathrm{Al}_{2} \mathrm{O}_{3}, 3.89 \% \mathrm{~K}_{2} \mathrm{O}, 3.61 \% \mathrm{Na}_{2} \mathrm{O}, 2.90 \% \mathrm{Fe}_{2} \mathrm{O}_{3}, 1.82 \% \mathrm{CaO}$ and small amounts of $\mathrm{Mg}, \mathrm{Ti}, \mathrm{S}, \mathrm{P}, \mathrm{Mn}, \mathrm{Ba}, \mathrm{Zr}, \mathrm{Cr}$ and $\mathrm{Zn}$. After washing with distilled water, it was oven dried at $50{ }^{\circ} \mathrm{C}$. Later, the particle size of dried pumice stone was ground particles smaller than $0.125 \mathrm{~mm}$. Iron (II) chloride tetrahydrate $\left(\mathrm{FeCl}_{2} \cdot 4 \mathrm{H}_{2} \mathrm{O}\right)$, sodium borohydride $\left(\mathrm{NaBH}_{4}\right)$ and ethanol were supplied by Sigma Aldrich. TC was provided by a pharmaceutical factory in Turkey. All chemicals were of analytical grade purity.

\subsection{Preparation of $n Z V I$ and P-nZVI}

nZVI and P-nZVI were synthesized using borohydride reduction method (Üzüm et al. 2009). $\mathrm{FeCl}_{2} \cdot 4 \mathrm{H}_{2} \mathrm{O}$ and sodiumborohydride $\left(\mathrm{NaBH}_{4}\right)$ were used and pumice was used as a support material [16]. Briefly, the preparation of P-nZVI composites had pumice to nZVI mass ratio of $1: 1,1: 2$ and $2: 1$. For the $1: 1 ; \mathrm{FeCl}_{2} \cdot 4 \mathrm{H}_{2} \mathrm{O}(5.34 \mathrm{~g})$ was dissolved in ethanol and water mixture $(30 \mathrm{~mL} ; 4: 1 \mathrm{v} / \mathrm{v})$, then $1.5 \mathrm{~g}$ of pumice was added to this solution and stirred for $30 \mathrm{~min}$. Meanwhile, a prepared 1.0 $\mathrm{M} \mathrm{NaBH}_{4}$ solution (3.05 $\mathrm{g} \mathrm{NaBH}_{4}$ in $100 \mathrm{~mL}$ of deionized water) was added dropwise into the pumice- $\mathrm{Fe}^{2+}$ mixture on the magnetic stirrer. Black solid particles of nZVI appeared immediately after the first drop of $\mathrm{NaBH}_{4}$ solution was added. After adding all of the borohydride solution, the mixture was left stirring for an additional $10 \mathrm{~min}$. The reduction of iron ions by borohydride ions can be represented by the following reaction (Wang et al. 2006):

$$
>\mathrm{Fe}^{2+}+2 \mathrm{BH}^{-}{ }_{4(\mathrm{aq})}+6 \mathrm{H}_{2} \mathrm{O} \rightarrow \mathrm{Fe}^{0}+2 \mathrm{~B}(\mathrm{OH})_{3}+7 \mathrm{H}_{2} \uparrow \text {. }
$$

The synthesized materials were separated from the liquid phase via the vacuum filtration. Solid particles were washed with absolute ethanol. The synthesized material was oven dried at $50{ }^{\circ} \mathrm{C}$. The pumice:nZVI mass ratios (1:2 and 2:1) were synthesized following the same method. nZVI and P-nZVI composites were stored in brown bottles for later use.

\subsection{Experiments with different pumice to $\mathrm{nZVI}$ mass ratios}

$0.05 \mathrm{~g}$ of P-nZVI prepared by different mass ratios of pumice to nZVI $(1: 1,1: 2$ and $2: 1)$ was added into $100 \mathrm{~mL}$ of $50 \mathrm{mg} / \mathrm{L}$ TC solutions. Solution $\mathrm{pH}$ values were adjusted to 4.00 by ADWA pH meter. The Erlenmeyer were shaken in a shaker at $200 \mathrm{rpm}$ for $60 \mathrm{~min}$. After centrifugation, the supernatant solutions were analyzed with a spectrophotometer (CHEBIOS) at $357 \mathrm{~nm}$ wavelength.

\subsection{Batch experiments}

Batch experiments were performed in Erlenmeyer with $100 \mathrm{~mL}$ of aqueous solution. Effect of nZVI and P-nZVI amounts $(2: 1)(2-10 \mathrm{~g} / \mathrm{L})$, solution $\mathrm{pH}(2-10)$, initial TC concentration $(25-300 \mathrm{mg} / \mathrm{L})$ and temperature $\left(25-45^{\circ} \mathrm{C}\right)$ on $T C$ removal using nZVI and P-nZVI was investigated. The solutions were shaken in a temperature controlled shaker (GERHARD) at $150 \mathrm{rpm}$. Sampling was made at a certain time-interval (5-180 $\mathrm{min})$ and then 
the supernatant solutions were transferred to falcon tubes. The samples were centrifuged by centrifugation (Hettich EBA 21). All experiments were performed in duplicate. The details of the experimental conditions are presented in Table 1.

\subsection{Characterization and analytical methods}

The adsorption capacity $\left(\mathrm{q}_{\mathrm{e}}, \mathrm{mg} / \mathrm{g}\right)$ is given below (Guler, Sarioglu 2014):

$$
q_{e}=\frac{\left([T C]_{o}-[T C]_{e}\right) V}{m},
$$

where $[T C]_{o}$ and $[T C]_{e}$ are the initial and the equilibrium concentration $(\mathrm{mg} / \mathrm{L}), V$ is the volume of solution $(\mathrm{L})$ and $m$ is the amount of nZVI and P-nZVI (g).

The removal efficiency of TC (\%) is described as follows (Guler, Sarioglu 2014):

$$
\operatorname{Sorption}(\%)=\frac{[T C]_{o}-[T C]_{e}}{[T C]_{o}} \times 100 .
$$

The nZVI and P-nZVI samples were collected after reacting with $T C$ solution for $5,10,15,30,60,120$ and $180 \mathrm{~min}$. Morphological analyses were performed using a scanning electron microscope (SEM) (LEO, 440) and transmission electron microscope (TEM) (JEOL JEM 1220). All TEM samples were prepared from depositing a drop of dilute ethanol solution of the nanoparticles onto a carbon film. The chemical bonds between the atoms and the functional groups of material were identified by FTIR method. The FTIR samples in $\mathrm{KBr}$ pellets were analyzed by a Perkin Elmer Spectrum 400 spectrometer. The crystalline phases of nZVI and P-nZVI were determined by used XRD diffractometer. A Cu Ka incident beam $(\lambda=$ $1.54 \mathrm{~nm}$ ) was used (Bruker AXS D8 Advance). The specific surface area (BET) was measured following the Brunauer-Emmett-Teller (BET) $\mathrm{N}_{2}$ method.

\section{Results and discussion}

\subsection{Characterization of materials}

The FTIR spectrum of the nZVI and P-nZVI composites before and after TC removal are shown in Figure 2. Broads bands at $3200-3600 \mathrm{~cm}^{-1}$ may have resulted from $\mathrm{O}-\mathrm{H}$ stretching. $\mathrm{O}-\mathrm{H}$ bending was observed at the $1645 \mathrm{~cm}^{-1}$ band. Bands at $<900 \mathrm{~cm}^{-1}$ in the nZVI may be related with iron oxides. These bands in the P-nZVI are weaker due to reduced oxidation of pumice modified $\mathrm{Fe}^{0}$. According to Kim et al. (2013), the pumice support may reduced Fe hydroxide formation. Similar results were obtained from other studies (Kim et al. 2013; Yuan et al. 2009). Bands at $1336-1128 \mathrm{~cm}^{-1}$ resulted from ethanol used in preparing the composites. Composites may include bands associated with sulfate green rust and lepidocrocite formation on some $\mathrm{Fe}^{0}$ surfaces (Kim et al. 2013; Andrade et al. 2009). The FT-IR spectra of TC-nZVI and TC-P-nZVI are different from those of nZVI and P-nZVI.

XRD spectrums of nZVI, TC-nZVI, P-nZVI, and TC-P-nZVI are presented in Figure 3. There were peaks at $22^{\circ}$ and $28^{\circ}$ in $\mathrm{P}-\mathrm{nZVI}$, which are associated with mineral dachiardite ( $\mathrm{Ca}, \mathrm{Na}, \mathrm{K}, \mathrm{Al}, \mathrm{Si}$ and $\mathrm{H}_{2} \mathrm{O}$ ) (Guler, Sarioglu 2014; Ersoy et al. 2010). The apparent peak at $44.9^{\circ}$ in $\mathrm{nZVI}$ and $\mathrm{P}-\mathrm{nZVI}$ indicated that $\mathrm{Fe}^{0}$ nanoparticles were modified onto the pumice surface (Chen et al. 2011; Fang et al. 2011; Zhang et al. 2011c). The peaks at $30^{\circ}$ and $33^{\circ}$ are related to $\mathrm{Fe}_{3} \mathrm{O}_{4} / \gamma-\mathrm{Fe}_{2} \mathrm{O}_{3}$ and $\mathrm{FeO}$, respectively. These iron oxides also appeared in P-nZVI (Zhang et al. 2011c; Kanel et al. 2005).

The SEM images of nZVI (a), P-nZVI (b), TC-nZVI (c), and TC-P-nZVI (d) are shown in Figure 4. The nZVI and P-nZVI composites were aggregated from the van der Waals and magnetic forces (Kim et al. 2013; Wang et al. 2013). The SEM images after reaction showed that the external surfaces of nZVI and P-nZVI were covered by TC.

Table 1. Experimental conditions for adsorption studies

\begin{tabular}{llcccccc}
\hline \multirow{2}{*}{ Set } & \multicolumn{6}{c}{ Experimental conditions } \\
\cline { 2 - 8 } & Aim of experiment & $\begin{array}{c}\text { Pumice:nZVI } \\
\text { mass ratio }\end{array}$ & $\mathrm{pH}$ & $\begin{array}{c}\text { TC conc. } \\
(\mathrm{mg} / \mathrm{L})\end{array}$ & $\begin{array}{c}\text { Adsorbent } \\
\text { amount }(\mathrm{g} / \mathrm{L})\end{array}$ & Contact time (min) & Temperature \\
\hline $\begin{array}{l}\text { Pumice:nZVI mass } \\
\text { ratio }\end{array}$ & $1.1,1: 2,2: 1$ & 4.0 & 50 & 5 & 60 & $25^{\circ} \mathrm{C}$ \\
\hline 2 & $\begin{array}{l}\text { Effect of nZVI and } \\
\text { P-nZVI amounts }\end{array}$ & $2: 1$ & 4.0 & 50 & $2-5-10$ & $5-10-15-30-60-120-180$ & $25^{\circ} \mathrm{C}$ \\
\hline 3 & Effect of pH value & $2: 1$ & $\begin{array}{c}2-4-6- \\
8-10\end{array}$ & 50 & 5 & $5-10-15-30-60-120-180$ & $25^{\circ} \mathrm{C}$ \\
\hline 4 & Adsorption isotherms & $2: 1$ & 8.0 & $\begin{array}{c}25-50-100- \\
200-300\end{array}$ & 5 & $5-10-15-30-60-120-180$ & $25^{\circ} \mathrm{C}$ \\
\hline 5 & Adsorption kinetics & $2: 1$ & 4.0 & 50 & 5 & $5-10-15-30-60-120-180$ & $25^{\circ} \mathrm{C}$ \\
\hline 6 & Effect of temperature & $2: 1$ & 8.0 & 50 & 5 & $5-10-15-30-60-120-180$ & $\begin{array}{c}25-35- \\
4 \circ^{\circ} \mathrm{C}\end{array}$ \\
\hline
\end{tabular}


a)

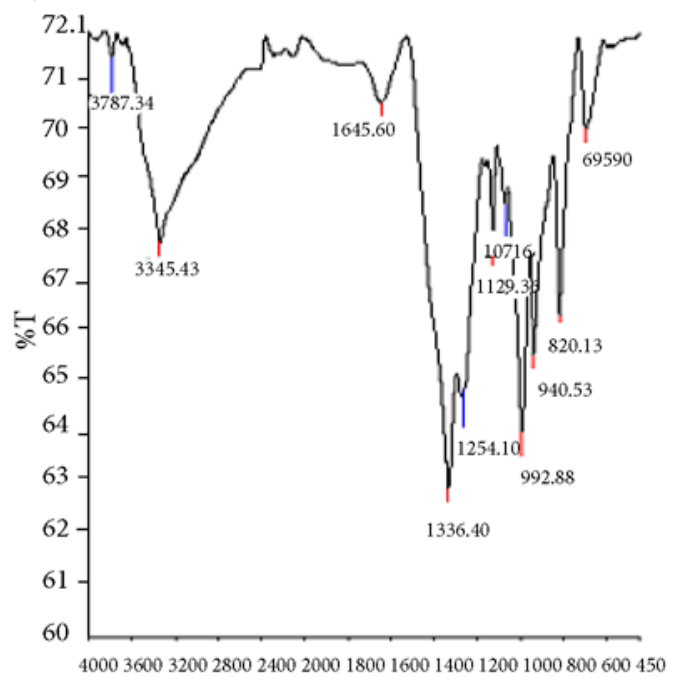

b)

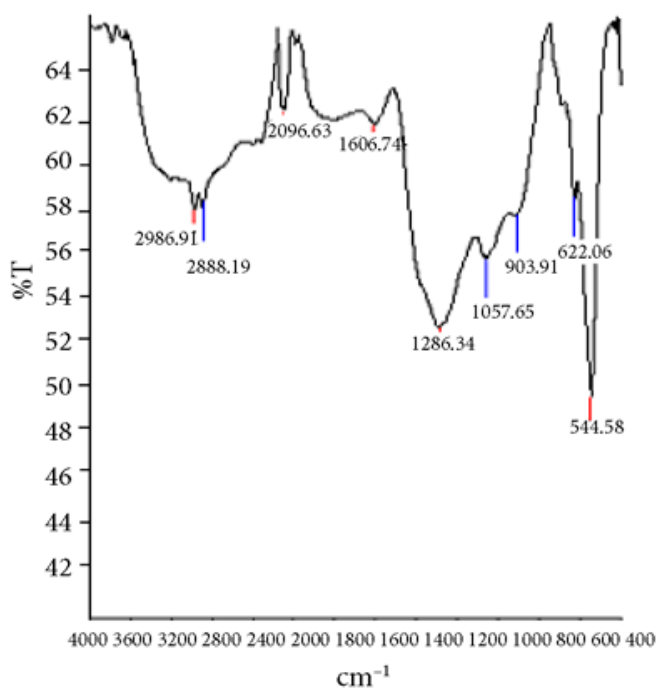

c)
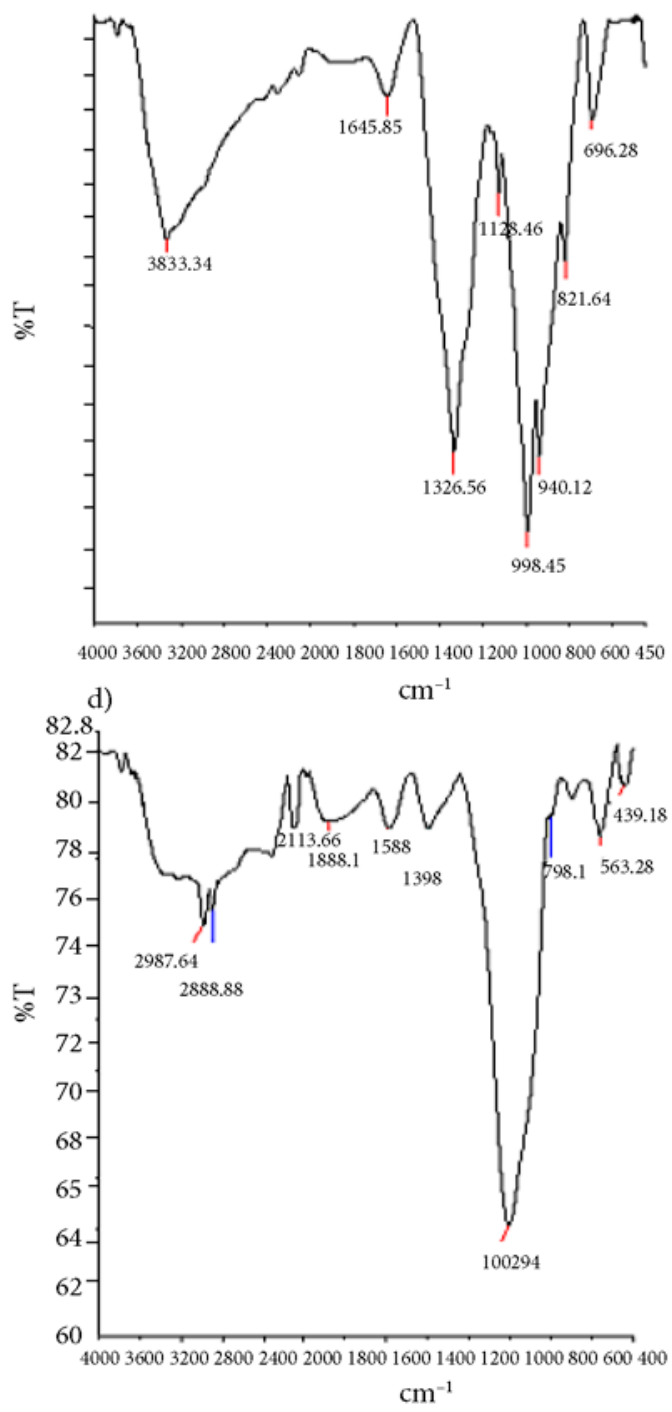

Fig. 2. FTIR patterns of nZVI (a), TC-nZVI (b), P-nZVI (c), and TC-P-nZVI (d)

In Figure 5 is presented TEM images of the nZVI and P-nZVI. The laboratory prepared nZVI and P-nZVI were spherical. TEM images also show that most particles formed chain-like aggregates (Sun et al. 2006). Aggregation of the nanoparticles is caused by the large surface area and magnetic dipole-dipole interactions of the particles. TEM analysis of a aged sample of nZVI showed that the chainlike structure was stil dominant but indicated also the presence of some larger floc aggregates, stemming possibly from the enhancement in oxide formation (Üzüm et al. 2008).

The BET surface area, total pore volume and mean pore size of $\mathrm{nZVI}$ and P-nZVI were $21.67 \mathrm{~m}^{2} \mathrm{~g}^{-1}$, $0.10 \mathrm{~cm}^{3} \mathrm{~g}^{-1}, 40 \mathrm{~nm}$ and $12,41 \mathrm{~m}^{2} \mathrm{~g}^{-1}, 0.05 \mathrm{~cm}^{3} \mathrm{~g}^{-1}, 27 \mathrm{~nm}$, respectively.

\subsection{Parameters affecting $T C$ removal}

\subsubsection{Pumice:nZVI mass ratio}

Figure 6a showed that removal efficiency of $T C$ increased the mass ratio as increased from 1:2 to 2:1. Using pumice as support material for nZVI created a synergetic effect for the TC removal process (Kim et al. 2013). Similar trends were reported for nitrate (Zhang et al. 2011b), organic contaminants (Zhang et al. 2011d) and Cr(VI) removal (Li et al. 2012).

\subsubsection{Effect of $n Z V I$ and $P-n Z V I$ amounts}

The removal efficiency of TC varied with contact time, from $5 \mathrm{~min}$ to $180 \mathrm{~min}$ under with different amounts of nZVI and P-nZVI (Fig. 6b). Removal efficiency of TC increased with increasing nZVI and P-nZVI amount and contact time. The removal efficiency of $T C$ increased from $67 \%$ to $77 \%$ and $37 \%$ to $52 \%$ by increasing amounts from 1 to $5 \mathrm{~g} / \mathrm{L}$ of nZVI and P-nZVI amount, respectively. Figure $4 \mathrm{~b}$ shows that $5 \mathrm{~g} / \mathrm{L} \mathrm{nZVI}$ and P-nZVI exhibited better removal efficiency than $1 \mathrm{~g} / \mathrm{L} \mathrm{nZVI}$ and P-nZVI. The removal efficiency of TC by nZVI was much higher than P-nZVI. These results may be explained with the more adsorptive and active surface sites (Chen et al. 2013). The 

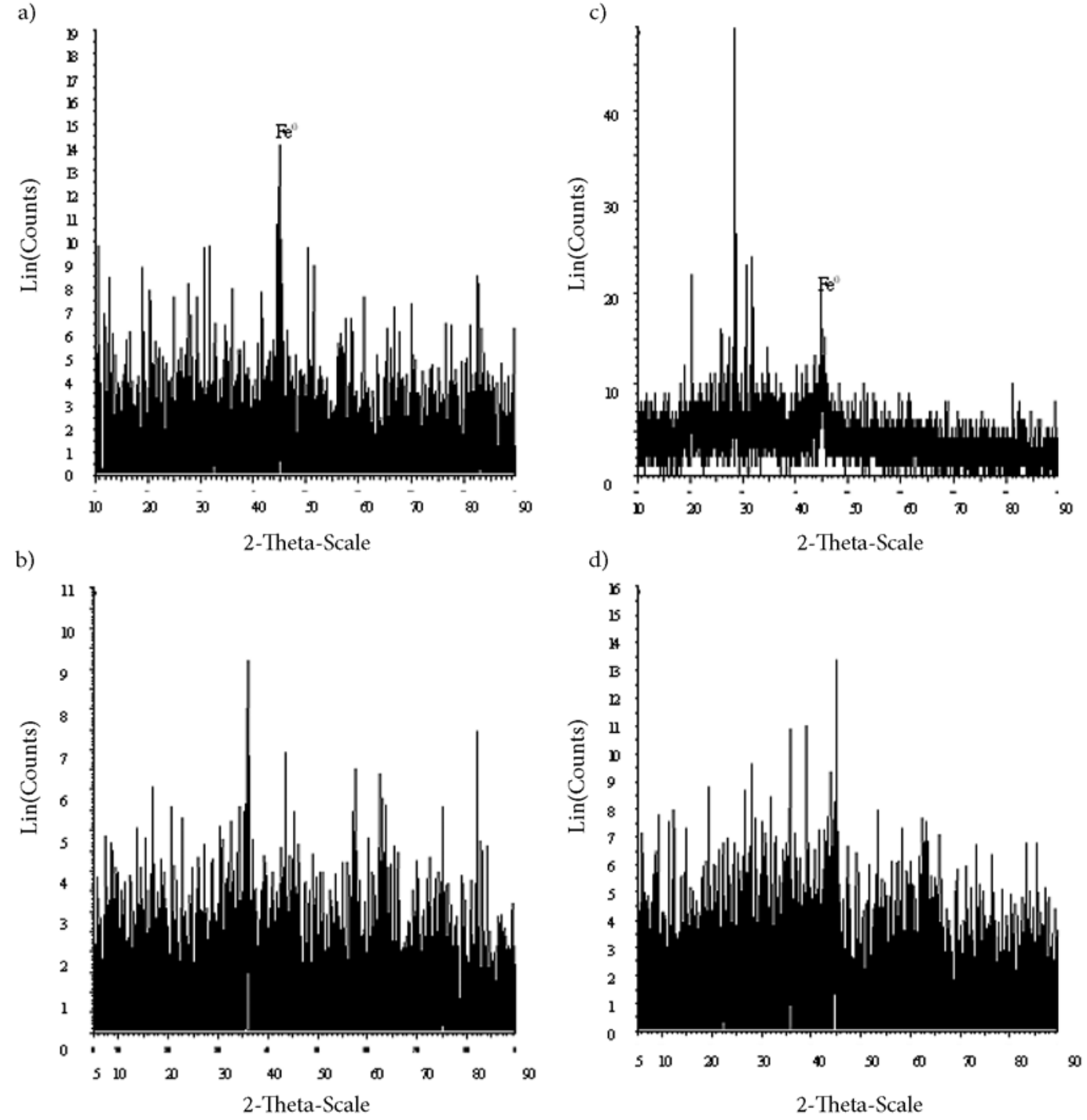

Fig. 3. XRD spectrums of nZVI (a), TC-nZVI (b), P-nZVI (c), and TC-P-nZVI (d)

a)

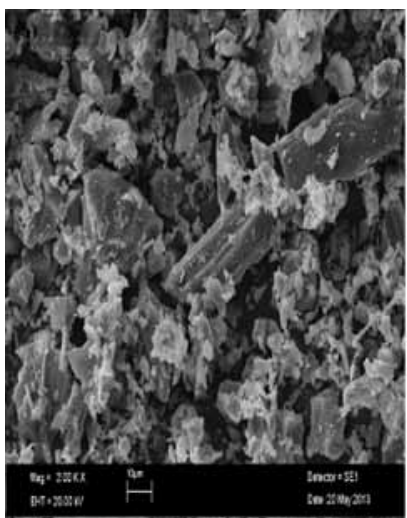

b)

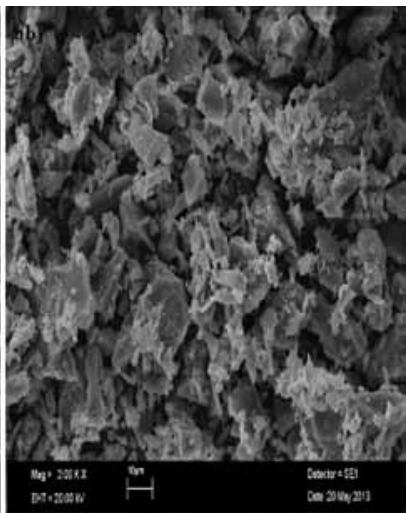

c)

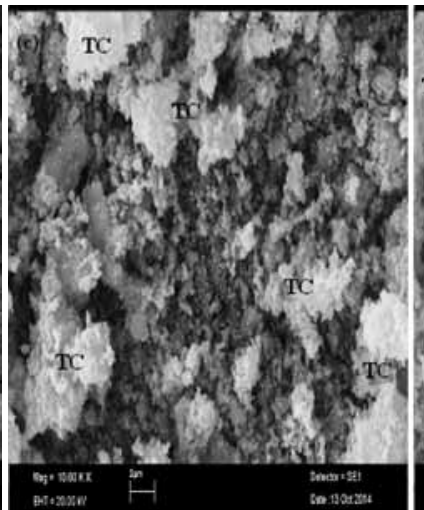

d)

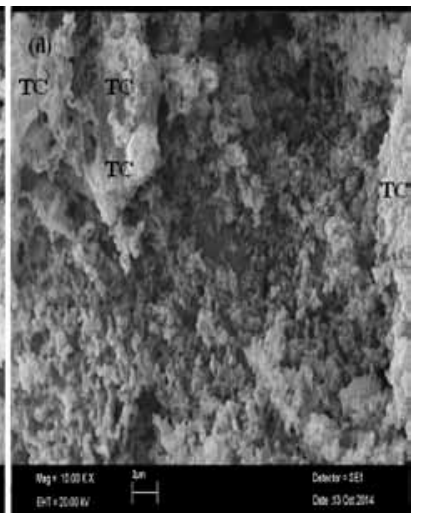

Fig. 4. SEM images of of nZVI (a), P-nZVI (b), TC-nZVI (c), and TC-P-nZVI (d) 
optimum dosage of nZVI and P-nZVI was selected as $5 \mathrm{~g} / \mathrm{L}$ which was used in further experiments.

\subsubsection{Effect of $p H$ value}

The $\mathrm{pH}$ is an important factor affecting removal efficiency of TC by iron (Chen et al. 2011). The effect of $\mathrm{pH}$ on the TC removal rates and the zero point of charge $\left(\mathrm{pH}_{\mathrm{pzc}}\right)$ are presented in Figure $6 \mathrm{c}$. The effects of different initial

a)

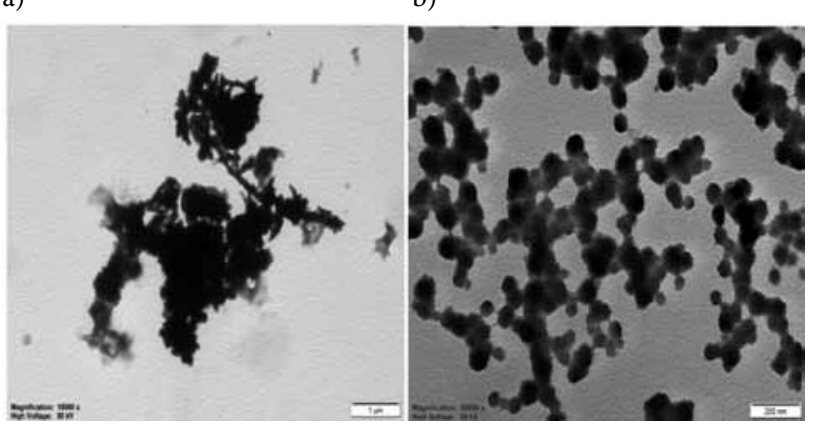

Fig. 5. TEM images of of nZVI (a), and P-nZVI (b) solution pH (2-4-6-8-10) were studied using a $100 \mathrm{~mL}$ solution containing $50 \mathrm{mgTC} / \mathrm{L}$ with contact times of 5-10-15-30-60-120-180 min. $\mathrm{pH}_{\mathrm{pzc}}$ values of nZVI and P-nZVI were found to be approximately 9.30.

After $180 \mathrm{~min}$ at $\mathrm{pH} 2,4$ and 6, the average removal efficiency of TC was approximately $92 \%$ and $88 \%$ for $\mathrm{nZVI}$ and P-nZVI; at pH 8 and $\mathrm{pH} 10$, it was approximately $88 \%$ and $72 \%$, respectively. At $\mathrm{pH}<3.3 ; 3.3<\mathrm{pH}<7.7$ and $7.70<\mathrm{pH}<9.70, \mathrm{H}_{3} \mathrm{TC}^{+}$(cationic), $\mathrm{H}_{2} \mathrm{TC}^{0}$ (zwitterionic) and HTC $^{-}$(anionic) species of TC were dominant (Zhao et al. 2012; Chen et al. 2011). When $\mathrm{pH}$ was lower than the $\mathrm{pH}_{\mathrm{PZC}}$ of $\mathrm{nZVI}$ and P-nZVI, the composites surface was positively charged. The removal mechanism might be via surface complexation and/or cation exchange on the surface sites (Fang et al. 2011). When $\mathrm{pH}$ was greater the $\mathrm{pH}_{\text {PZC }}$ of nZVI and P-nZVI, surfaces areas were negatively charged. In this situation, the decrease in removal efficiency may be explained by electrostatic repulsion between surface areas and TC molecules (Ersoy et al. 2010). At lower $\mathrm{pH}$, corrosion of $\mathrm{nZVI}$ composite was accelerated and $\mathrm{Fe}^{3+}-\mathrm{TC}$ hydroxides on the iron surface contributed to a)

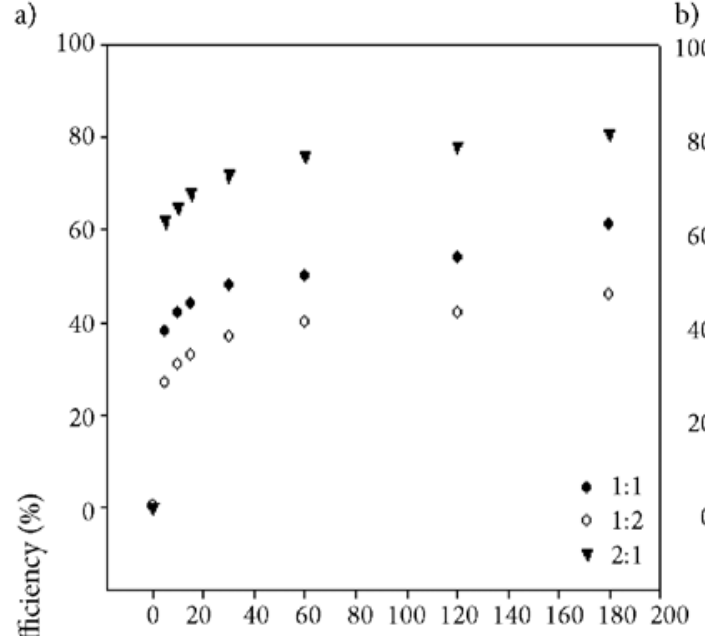

b)

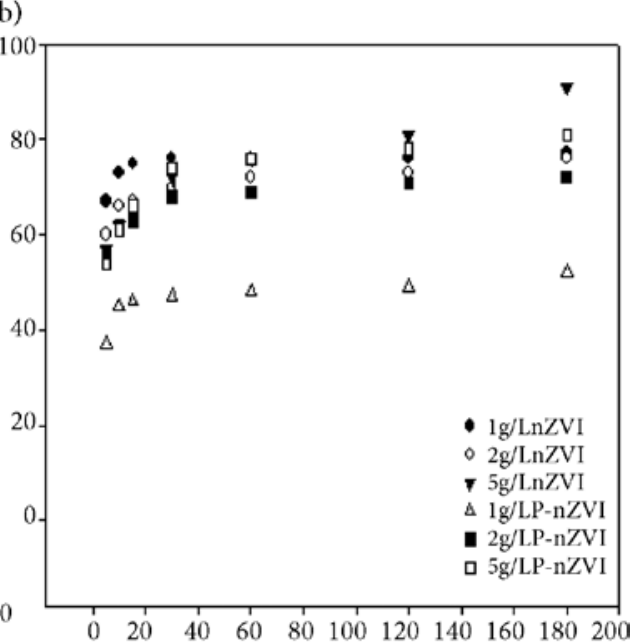

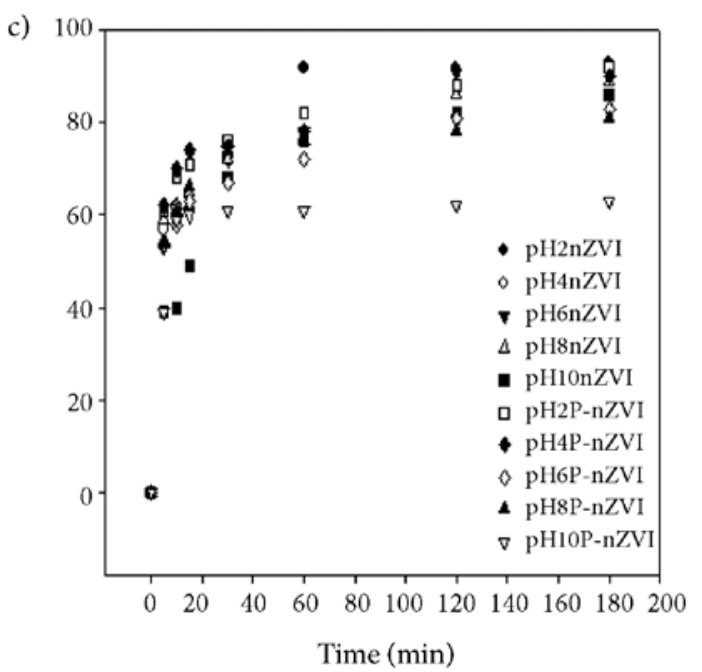

Fig. 6. Effect of different parameters on TC removal (a) mass ratios of pumice to nZVI (Conditions: $298 \mathrm{~K}, 200 \mathrm{rpm}, 50 \mathrm{mgTC} / \mathrm{L}$, $\mathrm{pH}_{\text {(initial) }}: 4.0,5 \mathrm{~g} / \mathrm{L}, 100 \mathrm{~mL}$ ), (b) adsorbent amount and $\mathrm{pH}_{\mathrm{PZC}}$ (Conditions: $298 \mathrm{~K}, 200 \mathrm{rpm}, 50 \mathrm{mgTC} / \mathrm{L}, \mathrm{pH}_{\text {(initial) }}: 4.0$, pumice:nZVI = 2:1, $100 \mathrm{~mL}$ ), (c) solution $\mathrm{pH}$ (Conditions: $5 \mathrm{~g} / \mathrm{L}, 298 \mathrm{~K}, 200 \mathrm{rpm}, 50 \mathrm{mgTC} / \mathrm{L}$, pumice:nZVI $=2: 1,100 \mathrm{~mL}$ ) 
the increase of TC removal (Li et al. 2012). Similarly, TC removal by $\mathrm{P}-\mathrm{nZVI}$ decreased when initial $\mathrm{pH}$ increased. The reason for this condition may have an additional effect of functional groups on pumice. These results indicated that the TC removal using nZVI and P-nZVI can be studied over a wide $\mathrm{pH}$ range.

\subsection{Adsorption isotherms}

The equations of the Langmuir, Freundlich and D-R models are given below (Guler, Sarioglu 2014; Gao et al. 2012):

$$
\begin{gathered}
q_{e}=\frac{Q_{m} b[T C]_{e}}{1+b[T C]_{e}} ; \\
q_{e}=k_{F}[T C]_{e}^{\frac{1}{n}} ; \\
q_{e}=q_{D-R} e^{\beta \varepsilon^{2}} ; \\
q_{e}=\frac{R T}{b_{T}} \ln \left(K_{T}[T C]_{e}\right),
\end{gathered}
$$

where, $[T C]_{e}(\mathrm{mg} / \mathrm{L})$ indicates the equilibrium concentrations in aqueous phase after the adsorption of TC on nZVI and P-nZVI. $\mathrm{q}_{\mathrm{e}}(\mathrm{mg} / \mathrm{g})$ is the equilibrium adsorption capacity of $\mathrm{nZVI}$ and P-nZVI. $Q_{m}(\mathrm{mg} / \mathrm{g})$ and $\mathrm{q}_{\mathrm{D}-\mathrm{R}}(\mathrm{mol} / \mathrm{g})$ are the maximum adsorption capacities, $b(\mathrm{~L} / \mathrm{mg}), k_{F}(\mathrm{~L} / \mathrm{g})$, and $\beta$ $\left(\mathrm{mol}^{2} / \mathrm{J}^{2}\right)$ are the constant of Langmuir, Freundlich and D-R models, respectively. $n$ and $\varepsilon(\mathrm{J} / \mathrm{mol})$ are the Freundlich linearity index and the Polanyi potential, respectively. The mean free energy $E(\mathrm{~kJ} / \mathrm{mol})$ is expressed as below:

$$
E=\frac{1}{\sqrt{2 \beta}} .
$$

Isotherm graphics are given in Figure $7 \mathrm{a}, \mathrm{b}$ and the isotherm parameters and correlation coefficients for TC are listed in Table 2.

As shown in Table 2, experimental data excellent fit both the Langmuir and Freundlich isotherm models (all exceed 0.960 ). Thus, the adsorption process occurred on a homogeneous adsorbent surfaces and on a reversible heterogeneous surfaces in the adsorption sites (Chen et al. 2013). The maximum adsorption capacity $\left(Q_{m}\right)$ of $T C$ for nZVI and P-nZVI was $105.46 \mathrm{mg} / \mathrm{g}$ and $115.13 \mathrm{mg} / \mathrm{g}$, respectively. These values were much higher than adsorptions capacities of other adsorbents (Table 3) (Li et al. 2010; Chen et al. 2011; Xu, Li 2010; Chang et al. 2009b; Figueroa et al. 2004). P-nZVI had a much higher b (L/mg) (Langmuir constant) than $\mathrm{nZVI}$, which verifies the advantageous TC adsorption of P-nZVI (Xu, Li 2010). The E value of adsorption was higher than $8 \mathrm{~kJ} / \mathrm{mol}$ for all results, suggesting that the adsorption mechanism may be a chemisorption.

\begin{tabular}{|c|c|c|c|c|c|c|c|c|c|}
\hline \multicolumn{10}{|c|}{ nZVI } \\
\hline \multicolumn{3}{|c|}{ Langmuir model } & \multicolumn{3}{|c|}{ Freundlich model } & \multicolumn{4}{|c|}{ D-R model } \\
\hline$Q_{m}(\mathrm{mg} / \mathrm{g})$ & $b(\mathrm{~L} / \mathrm{mg})$ & $R^{2}$ & $k_{F}(\mathrm{~L} / \mathrm{g})$ & $1 / n$ & $R^{2}$ & $q_{D-R}(\mathrm{~mol} / \mathrm{g})$ & $E(\mathrm{~kJ} / \mathrm{mol})$ & $\beta\left(\mathrm{mol}^{2} / \mathrm{J}^{2}\right)$ & $R^{2}$ \\
\hline 105.46 & 0.0063 & 0.962 & 2.267 & 0.62 & 0.979 & 0.0009 & 9.63 & $5.3978 .10^{-9}$ & 0.970 \\
\hline \multicolumn{10}{|c|}{ P-nZVI } \\
\hline \multicolumn{3}{|c|}{ Langmuir model } & \multicolumn{3}{|c|}{ Freundlich model } & \multicolumn{4}{|c|}{ D-R model } \\
\hline$Q_{m}(\mathrm{mg} / \mathrm{g})$ & $b(\mathrm{~L} / \mathrm{mg})$ & $R^{2}$ & $k_{F}(\mathrm{~L} / \mathrm{g})$ & $1 / n$ & $R^{2}$ & $q_{D-R}(\mathrm{~mol} / \mathrm{g})$ & $E(\mathrm{~kJ} / \mathrm{mol})$ & $\beta\left(\mathrm{mol}^{2} / \mathrm{J}^{2}\right)$ & $R^{2}$ \\
\hline 115.13 & 0.0070 & 0.970 & 2.356 & 0.65 & 0.982 & 0.0012 & 9.38 & $5.6889 .10^{-9}$ & 0.975 \\
\hline
\end{tabular}
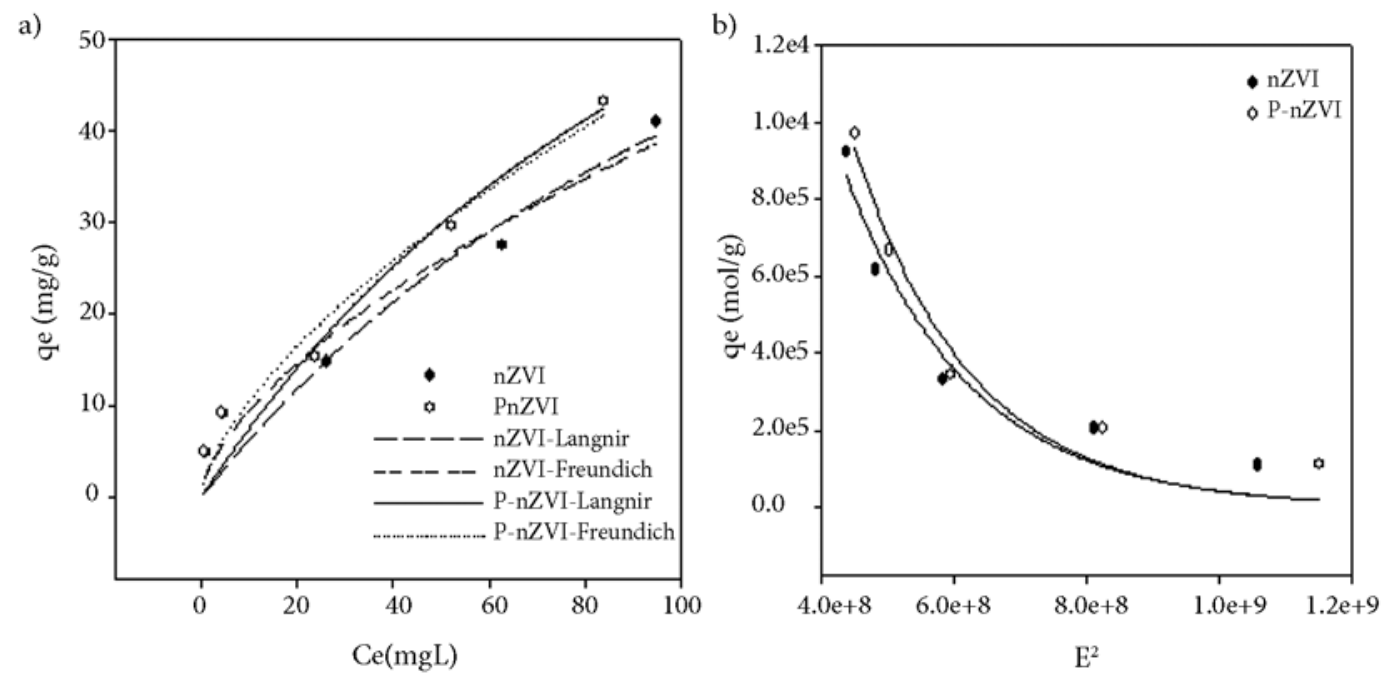

Fig. 7. Langmuir, Freundlich (a) and D-R (b) isotherm plots for adsorption of TC onto nZVI and P-nZVI

Table 2. Isotherm parameters and correlation coefficients of TC adsorption on nZVI and P-nZVI 
Table 3. TC adsorption capacities using different adsorbents

\begin{tabular}{lcl}
\hline \multicolumn{1}{c}{ Adsorbent } & $Q_{m}(\mathrm{mg} / \mathrm{g})$ & \multicolumn{1}{c}{ Reference } \\
\hline nZVI & 105.46 & This study \\
\hline P-nZVI & 115.13 & This study \\
\hline Kaolinite & 4.32 & (Li et al. 2010) \\
\hline Marine sediments & $16.7-33.3$ & $(\mathrm{Xu}$, Li 2010) \\
\hline Palygorskite & 61.8 & (Chang et al. 2009b) \\
\hline Montmorillonit & 54 & (Figueroa et al. 2004) \\
\hline
\end{tabular}

\subsection{Kinetic studies}

The TC removal on nZVI and P-nZVI was contained adsorption and reduction process.

\subsubsection{Adsorption kinetics}

The non-linear form of the pseudo-first order, pseudo-second order and intra particle models are applied to adsorption studies. These models depended on the physical and/ or chemical properties of the adsorbent (Chen et al. 2013). The pseudo-first-order model is given below:

$$
q_{t}=q_{e}\left(1-e^{-k_{1} t}\right),
$$

where $q_{e}$ and $q_{t}(\mathrm{mg} / \mathrm{g})$ are the amounts of TC molecules adsorbed on the nZVI and P-nZVI at equilibrium and different time and $k_{1}\left(\mathrm{~min}^{-1}\right)$ is the rate constant of the pseudo-first-order model for the adsorption process.

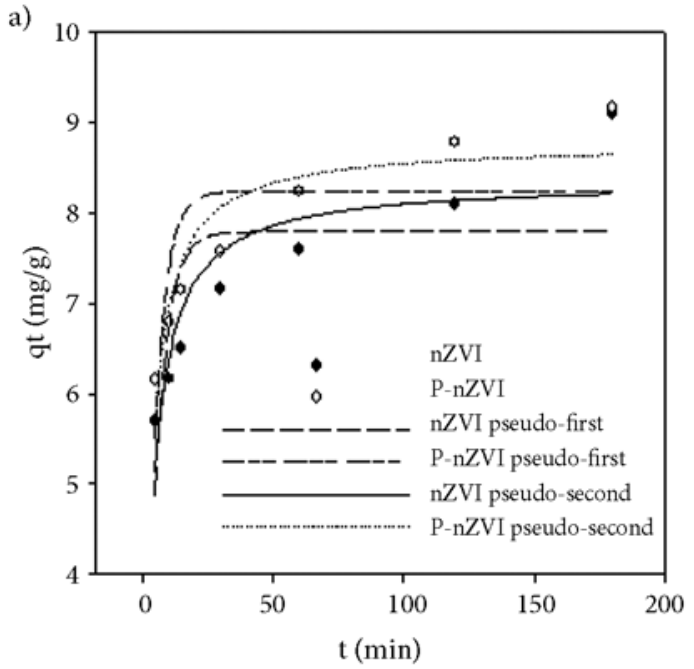

The pseudo-second-order model can be shown as follows:

$$
q_{t}=\frac{k_{2} q_{e}{ }^{2} t}{1+k_{2} q_{e} t}
$$

where $q_{e}$ and $q_{t}(\mathrm{mg} / \mathrm{g})$ are the amounts of TC molecules adsorbed on the nZVI and P-nZVI at equilibrium and different time and $k_{2}\left(\mathrm{~g} \cdot \mathrm{mg}^{-1} \mathrm{~min}^{-1}\right)$ is the rate constant of the pseudo-first-order model for the adsorption process.

Intraparticle model is given below:

$$
q t=k_{i} t^{0.5}+C
$$

where: $k_{\mathrm{i}}\left(\mathrm{mg} / \mathrm{g} \cdot \mathrm{min}^{0.5}\right)$ and $C$ are the rate constant of intraparticle diffusion model and the intercept, respectively. The larger the intercept is the greater is the contribution of the surface sorption in the rate controlling step. The plots of $q t v s$. $t$ for pseudo-first order and pseudo-second order kinetic model and the plot of $q t v s$. $t^{0.5}$ for intra particle model are presented in Figure $8 \mathrm{a}, \mathrm{b}$. The calculated coefficients and correlation coefficients are listed in Table 4.

According to the results, adsorption kinetics for all studies fit well with the pseudo-second-order model; the correlation coefficient $\left(R^{2}\right)$ ranged from 0.997 to 0.999 . This showed that the rate controlling step in adsorption process may be chemisorptions and TC adsorption occurs probably via van der Waals forces or ion exchange between the adsorbent and TC (Zhao et al. 2011; Wang et al. 2013). In addition, intraparticle diffusion model is

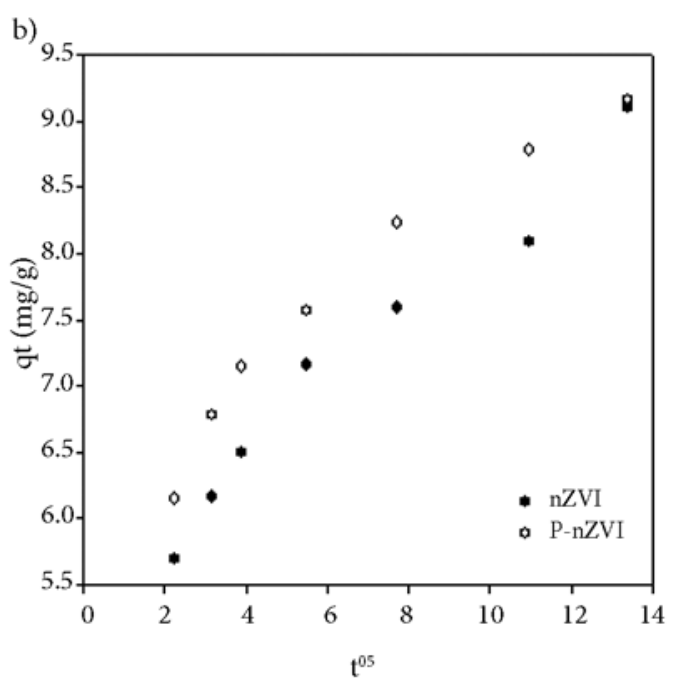

\begin{tabular}{|c|c|c|c|c|c|c|c|c|c|}
\hline \multirow[b]{2}{*}{$\begin{array}{c}q_{e, e x p} \\
(\mathrm{mg} / \mathrm{g})\end{array}$} & \multicolumn{3}{|c|}{ Pseudo-first order } & \multicolumn{3}{|c|}{ Pseudo-second order } & \multicolumn{3}{|c|}{ Intra particle diffusion } \\
\hline & $\begin{array}{c}k_{1} \\
\left(\min ^{-1}\right)\end{array}$ & $\begin{array}{c}q_{1} \\
(\mathrm{mg} / \mathrm{g})\end{array}$ & $R^{2}$ & $\begin{array}{c}k_{2} \\
\left(\mathrm{~g} \cdot \mathrm{mg}^{-1} \mathrm{~min}^{-1}\right)\end{array}$ & $\begin{array}{c}q_{2} \\
(\mathrm{mg} / \mathrm{g})\end{array}$ & $R^{2}$ & $\begin{array}{c}k_{\mathrm{i}} \\
\left(\mathrm{mg} / \mathrm{g} \cdot \min ^{0.5}\right)\end{array}$ & C & $R^{2}$ \\
\hline \multicolumn{10}{|c|}{ nZVI } \\
\hline 9.10 & 0.198 & 7.79 & 0.728 & 0.038 & 8.35 & 0.900 & 0.277 & 5.33 & 0.984 \\
\hline \multicolumn{10}{|c|}{ P-nZVI } \\
\hline 9.16 & 0.221 & 8.23 & 0.768 & 0.043 & 8.77 & 0.937 & 0.253 & 5.99 & 0.975 \\
\hline
\end{tabular}

Fig. 8. Pseudo-first, pseudo-second order kinetic (a) and intra particle model (b) of TC onto nZVI and P-nZVI

Table 4. Adsorption kinetic parameters of the TC removal by the nZVI and P-nZVI 
not the one rate controlling step due to it was not linear (Guler, Sarioglu 2014; Ersoy et al. 2010). Therefore; TC adsorption was affected both intra particle diffusion and boundary diffusion.

\subsubsection{Reduction kinetic}

The pseudo-first-order kinetic model was used for TC removal by nZVI and P-nZVI. Pseudo-first-order kinetics is showed as below (Chen et al. 2013; Zhang 2003):

$$
\ln \frac{[T C]_{e}}{[T C]_{o}}=-k_{o b s} t,
$$

where $k_{o b s}\left(\mathrm{~min}^{-1}\right)$ is the rate constant of a pseudo-firstorder kinetic model (Table 5). The removal of TC by nZVI and P-nZVI composites fitted well to the pseudofirst order kinetic model. The $k_{o b s}$ decreased for nZVI and P-nZVI as the initial TC concentration increased from 25 to $300 \mathrm{mg} / \mathrm{L}$, respectively. This indicated that the reduction of TC occurs at the interface of nZVI and P-nZVI (Chen et al. 2013; Shi et al. 2011). The rate of reduction was related to the active sites of adsorbent and the initial TC concentration (Chen et al. 2013). Moreover, the rate constants $k_{o b s}$ of P-nZVI were higher than nZVI. Pumice provided a mechanical supports and reactivity (Chen et al. 2013; Choi et al. 2009).

Table 5. $k_{o b s}$ for removal of $T C$

\begin{tabular}{lccc}
\hline \multirow{3}{*}{$T C$ conc $(\mathrm{mg} / \mathrm{L})$} & $k_{\text {obs }}\left(\mathrm{min}^{-1}\right)$ & $R^{2}$ \\
\hline \multirow{4}{*}{ nZVI } & 25 & 0.012 & 0.902 \\
\cline { 2 - 4 } & 50 & 0.007 & 0.959 \\
\cline { 2 - 4 } & 100 & 0.002 & 0.952 \\
\hline & 200 & 0.001 & 0.861 \\
\hline \multirow{3}{*}{ P-nZVI } & 300 & 0.002 & 0.943 \\
\cline { 2 - 4 } & 25 & 0.018 & 0.972 \\
\cline { 2 - 4 } & 50 & 0.008 & 0.964 \\
\cline { 2 - 4 } & 100 & 0.004 & 0.963 \\
\hline & 200 & 0.002 & 0.974 \\
\hline
\end{tabular}

\subsection{Thermodynamic parameters}

The standard free energy change $\left(\Delta G^{\mathrm{o}} ; \mathrm{kJ} / \mathrm{mol}\right)$, standart enthalpy change $\left(\Delta H^{\circ} ; \mathrm{kJ} / \mathrm{mol}\right)$ and standart entropy change $\left(\Delta S^{\mathrm{o}} ; \mathrm{kJ} / \mathrm{mol} . \mathrm{K}\right)$ were calculated using the following equations (Chen et al. 2013):

$$
\begin{gathered}
\Delta G^{o}=-R T \ln K_{c} ; \\
\ln K_{c}=\frac{\Delta S^{o}}{R}-\frac{\Delta H^{o}}{R T},
\end{gathered}
$$

where $T$ is the reaction temperature (Kelvin) and $K_{c}$ is the $q_{e} / C_{e} . \Delta H^{\circ}$ and $\Delta S^{\circ}$ were determined from a plot of $\ln K_{L}$ versus $1 / T$. The thermodynamic parameters are listed in Table 6.
Table 6. Thermodynamic parameters obtained for $T C$ removal onto nZVI and P-nZVI composites

\begin{tabular}{lccccc}
\hline & $\begin{array}{c}\Delta H^{o} \\
(\mathrm{~kJ} / \mathrm{mol})\end{array}$ & $\begin{array}{c}\Delta S^{o} \\
(\mathrm{~kJ} / \mathrm{mol} \cdot \mathrm{K})\end{array}$ & \multicolumn{4}{c}{$\Delta G^{o}(\mathrm{~kJ} / \mathrm{mol})$} \\
\hline & & & $298 \mathrm{~K}$ & $308 \mathrm{~K}$ & $318 \mathrm{~K}$ \\
\hline nZVI & -2.87 & 52.84 & -18.85 & -18.82 & -19.93 \\
\hline P-nZVI & -17.95 & -0.51 & -19.13 & -17.44 & -17.93 \\
\hline
\end{tabular}

Negative values of $\Delta G^{o}$ and $\Delta H^{\circ}$ indicate that $T C$ adsorption was spontaneous, feasible and exothermic. The negative value of $\Delta S$ showed that the adsorption process is due to an associative mechanism and decreased randomness. The negative $\Delta S$ value $(-0.51 \mathrm{~kJ} / \mathrm{mol}$ for $\mathrm{P}-\mathrm{nZVI})$ mean that the decreased randomness at the solid/liquid interface during adsorption.

\subsection{Proposed mechanism for $T C$ removal by nZVI and P-nZVI}

The core and shell structure of nZVI composites provide two uptake mechanisms. The core is an electron source and can reduce ions, so it has a higher reduction potential than iron. The shell has hydroxyl groups and it provides uptake on the nZVI surface of adsorbate via surface complexation (Üzüm et al. 2009).

Based on the results presented here, possible mechanisms for TC removal from aqueous solutions involves (i) TC adsorption by nZVI and P-nZVI and (ii) TC reduction via oxidation of $\mathrm{Fe}^{0}$ to $\mathrm{Fe}^{3+}$ ( $\mathrm{Li}$ et al. 2012; Chen et al. 2013; Zhang et al. 2012). The yellow flocculent precipitates were observed, indicating that $\mathrm{TC}_{x} \mathrm{Fe}_{(1-x)}(\mathrm{OH})_{3}$ complexes were formed. Similar results were reported by other researches (Chen et al. 2011). Possible reactions and mechanism are as follows (Eqs (15)-(19) and Fig. 9):

$$
\begin{gathered}
\text { TC }+ \text { nZVI or P-nZVI } \rightarrow \text { TC-nZVI or } \\
\text { TC-P-nZVI (adsorption); }
\end{gathered}
$$

$$
T C+\mathrm{Fe}^{0}+2 \mathrm{H}^{+} \rightarrow \mathrm{Fe}^{2+}+\mathrm{H}_{2}+T C+2 \mathrm{e}^{-}
$$

(oxidation in acidic solution);

$$
\begin{aligned}
& \mathrm{TC}+\mathrm{Fe}^{0}+2 \mathrm{H}_{2} \mathrm{O} \rightarrow \mathrm{Fe}^{2+}+\mathrm{H}_{2}+2 \mathrm{OH}^{-}+\mathrm{TC}+2 \mathrm{e} \\
& \text { (oxidation in basic solution); }
\end{aligned}
$$

$$
\begin{gathered}
T C+2 \mathrm{Fe}^{2+}+2 \mathrm{H}^{+}+1 / 2 \mathrm{O}_{2} \rightarrow \mathrm{Fe}^{3+}+T C+\mathrm{H}_{2} \mathrm{O} \\
\text { (oxidation in acidic solution) }
\end{gathered}
$$

$$
\begin{gathered}
x T C+(1-x) \mathrm{Fe}^{3+}+3 \mathrm{H}_{2} \mathrm{O} \rightarrow T C_{x} \mathrm{Fe}_{(1-x)}(\mathrm{OH})_{3}+3 \mathrm{H}^{+} \\
\text {(reduction). }
\end{gathered}
$$

\section{Conclusions}

This study demonstrated that nZVI and P-nZVI composites can be used successfully used for TC removal in 

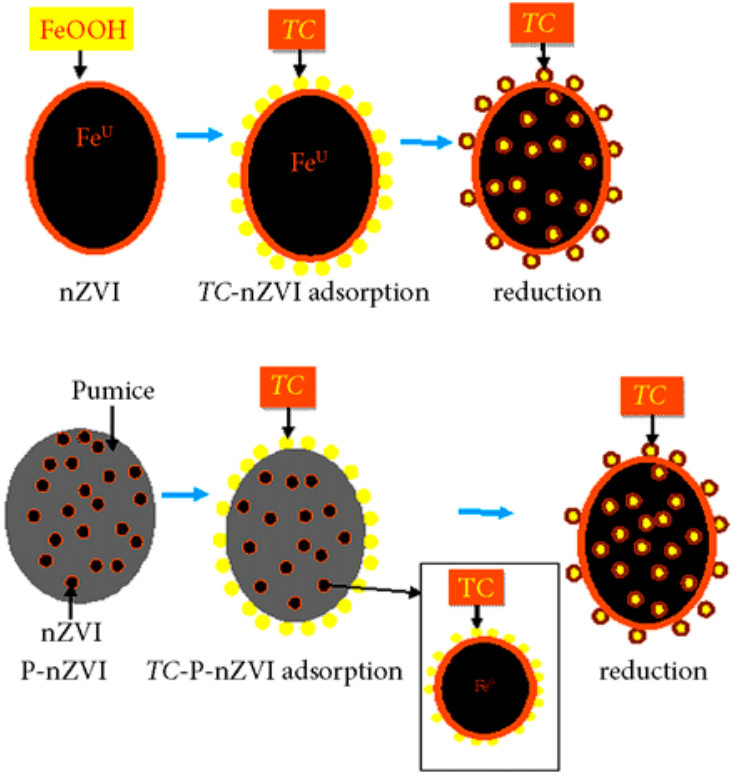

Fig. 9. Proposed mechanism for TC removal by nZVI and P-nZVI

aqueous solutions. Pumice was an effective support material as a dispersant and stabilizer that reduced nZVI aggregation. Mean pore diameters of nZVI and P-nZVI were $40 \mathrm{~nm}$ and $27 \mathrm{~nm}$, respectively. $\mathrm{pH}$ significantly affects removal efficiency. FTIR, XRD, SEM and TEM analyses indicated that nZVI particles were dispersed on the surface of pumice and aggregation of nZVI was decreased. The removal of TC by nZVI and P-nZVI may comprise two processes: (i) reduction (ii) adsorption.

Finally, the high removal efficiency (91\% and $92 \%$ for nZVI and P-nZVI, respectively) demonstrated that nZVI and P-nZVI are promising materials for treating pharmaceutical compounds in wastewaters.

\section{Acknowledgements}

This work was supported by the Scientific Research Project Fund of Cumhuriyet University under Grant [number M-479].

\section{References}

Andrade, A. L.; Souza, D. M.; Pereira, M. C.; Fabris, J. D.; Domingues, R. Z. 2009. Synthesis and characterization of magnetic nanoparticles coated with silica through a sol-gel approach, Ceramica 55: 420-424.

http://dx.doi.org/10.1590/S0366-69132009000400013

Asgari, G.; Roshani, B.; Ghanizadeh, G. 2012. The investigation of kinetic and isotherm of fluoride adsorption onto functionalize pumice stone, Journal of Hazardous Materials 17(218): 123-132. http://dx.doi.org/10.1016/j.jhazmat.2012.03.003

Boxall, A. B. A.; Kolpin, D. W.; SØrensen, B. H.; Tolls, J. 2003. Are veterinary medicines causing environmental risks?, Environmental Science \& Technolgy 37: 286-294.

http://dx.doi.org/10.1021/es032519b
Cao, J. S.; Zhang, W. X. 2006. Stabilization of chromium ore processing residue (COPR) with nanoscale iron particles, Journal of Hazardous Materials 132: 213-219. http://dx.doi.org/10.1016/j.jhazmat.2005.09.008

Chang, P. H.; Li, Z. H.; Yu, T. L.; Munkhbayer, S.; Kuo, T. H.; Hung, Y. C.; Jean, J. S.; Lin, K. H. 2009b. Sorptive removal of tetracycline from water by palygorskite, Journal of Hazardous Materials 165: 148-155. http://dx.doi.org/10.1016/j.jhazmat.2008.09.113

Chang, P. H.; Li, Z.; Jean, J. S.; Jiang, W. T.; Wang, C. J.; Lin, K. H. 2009a. Adsorption and intercalation of tetracycline by swelling clay minerals, Applied Clay Science 46: 27-36. http://dx.doi.org/10.1016/j.clay.2009.07.002

Chang, P. H.; Li, Z.; Jean, J. S.; Jiang, W. T.; Wang, C. J.; Lin, K. H. 2012. Adsorption of tetracycline on 2:1 layered non-swelling clay mineral illite, Applied Clay Science 67-68: 158-163. http://dx.doi.org/10.1016/j.clay.2011.11.004

Chen, H.; Luoa, H.; Lana, Y.; Donga, T.; Hub, B.; Wang, Y. 2011. Removal of tetracycline from aqueous solutions using polyvinylpyrrolidone (PVP-K30) modified nanoscale zero valent iron, Journal of Hazardous Materials 192: 44-53. http://dx.doi.org/10.1016/j.jhazmat.2011.04.089

Chen, Z.; Wang, T.; Jin, X.; Chen, Z.; Megharaj, M.; Naidu, R. 2013. Multifunctional kaolinite-supported nanoscale zerovalent iron used for the adsorption and degradation of crystal violet in aqueous solution, Journal of Colloid Interface Science 398: 59-66. http://dx.doi.org/10.1016/j.jcis.2013.02.020

Choi, H.; Al-Abed, S. R.; Agarwal, S. 2009. Catalytic role of palladium and relative reactivity of substituted chlorines during trapping and treatment of PCBs on reactive activated carbon, Environmental Science \& Technolgy 43: 7510-7515. http://dx.doi.org/10.1021/es901298b

Cumbal, L.; Greenleaf, J.; Leun, D.; Sen-Gupta, A. K. 2003. Polymer supported inorganic nanoparticles: characterization and environmental applications, Reactive \& Functional Polymers 54: $167-180$.

http://dx.doi.org/10.1016/S1381-5148(02)00192-X

Daughton, C. G.; Ternes, T. A. 1999. Pharmaceuticals and personal care products in the environment: agents of subtle change?, Environmental Health Perspectives 107: 907-938. http://dx.doi.org/10.1289/ehp.99107s6907

Dickinson, M.; Scott, T. B. 2010. The application of zero-valent iron nanoparticles for the remediation of a uranium-contaminated waste effluent, Journal of Hazardous Materials 178: 171-179. http://dx.doi.org/10.1016/j.jhazmat.2010.01.060

Ersoy, B.; Sariisik, A.; Dikmen, S.; Sariisik, G. 2010. Characterization of acidic pumice and determination of its electrokinetic properties in water, Powder Technology 197: 129-135. http://dx.doi.org/10.1016/j.powtec.2009.09.005

Fang, Z.; Chen, J.; Qiu, X.; Qiu, X.; Cheng, W.; Zhu, L. 2011. Effective removal of antibiotic metronidazole from water by nanoscale zero-valent iron particles, Desalination 268: 60-67. http://dx.doi.org/10.1016/j.desal.2010.09.051

Figueroa, R. A.; Leonard, A.; MacKay, A. A. 2004. Modeling tetracycline antibiotic sorption to clays, Environmental Science \& Technolgy 38: 476-483. http://dx.doi.org/10.1021/es0342087

Gao, Y.; Li, Y.; Zhang, L.; Huang, H.; Hu, J.; Shah, S. M.; Su, X. 2012. Adsorption and removal of tetracycline antibiotics from aqueous solution by graphene oxide, Journal of Colloid Interface Science 368: 540-546.

http://dx.doi.org/10.1016/j.jcis.2011.11.015 
Guler, U. A.; Sarioglu, M. 2014. Removal of tetracycline from wastewater using pumice stone: equilibrium, kinetic and thermodynamic studies, Journal of Environmental Health 12: 79. http://dx.doi.org/10.1186/2052-336x-12-79

Kanel, S. R.; Greneche, J. M.; Choi, H. 2006. Arsenic (V) removal from groundwater using nanoscale zero-valent iron as a colloidal reactive barrier material, Environmental Science \& Technolgy 40: 2045-2050. http://dx.doi.org/10.1021/es0520924

Kanel, S. R.; Manning, B.; Charlet, L.; Choi, H. 2005. Removal of arsenic (III) from groundwater by nanoscale zero-valent iron, Environmental Science \& Technolgy 39: 1291-1298. http://dx.doi.org/10.1021/es048991u

Kim, S. A.; Kannan, S. K.; Lee, K. J.; Park, Y. J.; Shea, P. J.; Lee, W. H.; Ki, H. M.; Oh, B. T. 2013. Removal of Pb(II) from aqueous solution by a zeolite-nanoscale zero-valent iron composite, Chemical Engineering Journal 217: 54-60. http://dx.doi.org/10.1016/j.cej.2012.11.097

Kitis, M.; Kaplan, S. S.; Karakaya, E.; Yigit, N. O.; Civelekoglu, G. 2007. Adsorption of natural organic matter from waters by iron coated pumice, Chemosphere 66: 130-138. http://dx.doi.org/10.1016/j.chemosphere.2006.05.002

Li, Y.; Li, J.; Zhang, Y. 2012. Mechanism insights into enhanced $\mathrm{Cr}(\mathrm{VI})$ removal using nanoscale zerovalent iron supported on the pillared bentonite by macroscopic and spectroscopic studies, Journal of Hazardous Materials 227-228: 211-218. http://dx.doi.org/10.1016/j.jhazmat.2012.05.034

Li, Z.; Schulz, L.; Ackley, C.; Fenske, N. 2010. Adsorption of tetracycline on kaolinite with $\mathrm{pH}$-dependent surface charges, Journal of Colloid and Interface Science 351: 254-260. http://dx.doi.org/10.1016/j.jcis.2010.07.034

Liu, T.; Wang, Z. L.; Yan, X.; Zhang, B. 2014. Removal of mercury (II) and chromium (VI) from wastewater using a new and effective composite: pumice-supported nanoscale zero-valent iron, Chemical Engineering Journal 245: 34-40. http://dx.doi.org/10.1016/j.cej.2014.02.011

Moraci, N.; Calabrò, P. S. 2010. Heavy metals removal and hydraulic performance in zero-valent iron/pumice permeable reactive barriers, Journal of Environmental Management 91: 2336-2341. http://dx.doi.org/10.1016/j.jenvman.2010.06.019

Shi, L. N.; Lin, Y. M.; Zhang, X.; Chen, Z. L. 2011. Synthesis, characterization and kinetics of bentonite supported nZVI for the removal of $\mathrm{Cr}$ (VI) from aqueous solution, Chemical Engineering Journal 171(2): 612-617.

http://dx.doi.org/10.1016/j.cej.2011.04.038

Song, X.; Liu, D.; Zhang, G.; Frigon, M.; Meng, X.; Li, K. 2014. Adsorption mechanisms and the effect of oxytetracycline on activated sludge, Bioresource Technology 151: 428-431. http://dx.doi.org/10.1016/j.biortech.2013.10.055

Üzüm, Ç.; Shahwan, T.; Eroglu, A. E.; Hallam, K. R.; Scott, T. B.; Lieberwirth, I. 2009. Synthesis and characterization of kaolinite-supported zero-valent iron nanoparticles and their application for the removal of aqueous $\mathrm{Cu}^{2+}$ and $\mathrm{Co}^{2+}$ ions, Applied Clay Science 43: 172-181.

http://dx.doi.org/10.1016/j.clay.2008.07.030

Wang, T.; Su, J.; Jina, X.; Chena, Z.; Megharaj, M.; Naidu, R. 2013. Functional clay supported bimetallic nZVI/Pd nanoparticles used for removal of methyl orange from aqueous solution, Journal of Hazardous Materials 262: 819-825. http://dx.doi.org/10.1016/j.jhazmat.2013.09.028

Wang, W.; Jin, Z.; Li, T.; Zhang, H.; Gao, S. 2006. Preparation of spherical iron nanoclusters in ethanol-water solution for nitrate removal, Chemosphere 65: 1396-1404. http://dx.doi.org/10.1016/j.chemosphere.2006.03.075

$\mathrm{Xu}, \mathrm{X}$. R.; Li, X. Y. 2010. Sorption and desorption of antibiotic tetracycline on marine sediments, Chemosphere 78: 430-436. http://dx.doi.org/10.1016/j.chemosphere.2009.10.045

Yuan, P.; Fan, M.; Yang, D.; He, H.; Liu, D.; Yuan, A.; Zhu, J.; Chen, T. 2009. Montmorillonite-supported magnetite nanoparticles for the removal of hexavalent chromium $\mathrm{Cr}(\mathrm{VI})$ from aqueous solutions, Journal of Hazardous Materials 166: 821-829. http://dx.doi.org/10.1016/j.jhazmat.2008.11.083

Zhang, D.; Niu, H.; Zhang, X.; Meng, Z.; Cai, Y. 2011a. Strong adsorption of chlorotetracyline on magnetite nanoparticles, Journal of Hazardous Materials 92: 1088-1093. http://dx.doi.org/10.1016/j.jhazmat.2011.06.015

Zhang, W. 2003. Nanoscale iron particles for environmental remediation: an overview, Journal of Nanoparticle Research 5: 323-332. http://dx.doi.org/10.1023/A:1025520116015

Zhang, X.; Lin, S.; Chen, Z.; Megharaj, M.; Naidu, R. 2011c. Kaolinite-supported nanoscale zero-valent iron for removal of $\mathrm{Pb}^{2+}$ from aqueous solution: reactivity, characterization and mechanism, Water Research 45: 3481-3488. http://dx.doi.org/10.1016/j.watres.2011.04.010

Zhang, X.; Lin, S.; Lu, X. Q.; Chen, Z. I. 2010. Removal of Pb (II) from water using synthesized kaolin supported nanoscale zero-valent iron, Chemical Engineering Journal 163: 243-248. http://dx.doi.org/10.1016/j.cej.2010.07.056

Zhang, Y.; Li, Y.; Li, J.; Hu, L.; Zheng, X. 2011b. Enhanced removal of nitrate by a novel composite: nanoscale zero valent iron supported on pillared clay, Chemical Engineering Journal 171: 526-531. http://dx.doi.org/10.1016/j.cej.2011.04.022

Zhang, Y.; Li, Y.; Zheng, X. 2011d. Removal of atrazine by nanoscale zero valent iron supported on organobentonite, Science of the Total Environment 409: 625-630. http://dx.doi.org/10.1016/j.scitotenv.2010.10.015

Zhao, Y.; Geng, J.; Wang, X.; Gu, X.; Gao, S. 2011. Adsorption of tetracycline onto goethite in the presence of metal cations and humic substances, Journal of Colloid and Interface Science 361: 247-251. http://dx.doi.org/10.1016/j.jcis.2011.05.051

Zhao, Y.; Gu, X.; Gao, S.; Geng, J.; Wang. X. 2012. Adsorption of tetracycline (TC) onto montmorillonite: cations and humic acid effects, Geoderma 183-184: 12-18.

http://dx.doi.org/10.1016/j.geoderma.2012.03.004

Ulker Asli GULER. Doctor of Environmental Science (2010). Ass. Prof. Dr of Environmental Engineering Department of Cumhuriyet University. Research interest: wastewater treatment, adsorption/biosorption, environmental technologies. 